Proceedings of the MACPROGEN Final Conference held at Ohrid, Republic of Macedonia, March 29-April 12012

\title{
RAPID AND NON INVASIVE PRENATAL DIAGNOSIS
}

\author{
Madjunkova $\mathrm{S}^{1}$, Sukarova-Stefanovska $\mathrm{E}^{1}$, Kocheva $\mathrm{S}^{2}$,Maleva $\mathrm{I}^{1}$, Noveski $\mathrm{P}^{1}$,
} Kiprijanovska $\mathrm{S}^{1}$, Stankova $\mathrm{K}^{3}$,Dimcev $\mathrm{P}^{4}$, Madjunkov $\mathrm{M}^{5}$, Plaseska-Karanfilska D ${ }^{1, *}$

\begin{abstract}
*Corresponding Author: Professor Dr. Dijana Plaseska-Karanfilska, Research Centre for Genetic Engineering and Biotechnology "Georgi D. Efremov," Macedonian Academy of Sciences and Arts, Krste Misirkov 2, Skopje 1000, Republic of Macedonia; Tel: +389(0)23235-410; Fax: +389 (0)2-3115-434; E-mail:dijana@manu.edu.mk
\end{abstract}

\section{INTRODUCTION}

Prenatal screening and diagnosis are routinely offered at antenatal care clinic visits, and are important in decision making about the continuation of pregnancies affected by genetic conditions for which there are no cures, and prevention through therapeutic abortion is a reasonable option. Prenatal screening is offered to all pregnant women and include fetal ultrasonography and maternal serum biochemistry to select the pregnancies at-risk for chromosomal abnormalities. However, these methods have limited sensitivities (60.0-75.0\%) and specificities (false positive rate of 5.0\%). Even when used in combination and taking into account maternal age, the identification rate of affected fetuses does not exceed $90.0 \%$ [one]. Prenatal diagnosis is usually preformed for detection of chromo-

1 Macedonian Academy of Sciences and Arts, Research Centre for Genetic Engineering and Biotechnology "Georgi D. Efremov," Skopje, Republic of Macedonia

2 Pediatric Clinic, Medical Faculty, University "Stt. Cyril and Methodius", Skopje, Republic of Macedonia

3 Private Health Organisation "Dr. Ina," Skopje, Republic of Macedonia

4 Private Health Organisation "Sistina," Skopje, Republic of Macedonia

5 Clinic for Gynaecology and Obstetrics, Faculty of Medicine, Skopje, Republic of Macedonia somal aneuploidies or monogenic diseases in "high risk" pregnancies. Diagnostic testing currently requires a sample of fetal cells obtained either by chorionic villus sampling (CVS) between 10 and 14 weeks gestation or by amniocentesis after 15 weeks of gestation. However, these invasive procedures carry a risk of miscarriage of around 1.0\% [2].

Prenatal Diagnosis of Chromosomal Abnormalities. Chromosomal abnormalities (numerical or structural) occur in 1 of 160 live births, with extra copies of chromosomes 21,18 , and 13 accounting for the majority of numerical alterations that are not related to sex chromosomes. The prevalence of trisomies is highest in the first trimester because of subsequent miscarriage and demise of aneuploid conceptuses during pregnancy [3]. Conventional cytogenetic techniques (karyotyping) are usually used to detect aneuploidies and large (5$10 \mathrm{Mb}$ ) rearrangements in fetal cells (amniocytes, trophoblasts), however, these are time-consuming (2-3 weeks), subjective (small rearrangements) and expensive. The development of molecular methods for the rapid, targeted detection of aneuploidies of chromosomes 13,18, 21 and the sex chromosomes by quantitative fluorescent polymerase chain reaction (QF-PCR) $[4,5]$ using fetal DNA, do not provide a genome-wide screen for unexpected imbalances, but are rapid (24-48 hours), accurate and inexpensive. Multiplex ligation probe amplification (MLPA) is a recent technique for relative quantita- 
tion of up to 40 to 45 nucleic acid targets. Several MLPA commercial kits are used for prenatal detection of common aneuploidies (chromosomes 13, 18, $21, \mathrm{X}$ and $\mathrm{Y}$ ), common microdeletion syndromes and subtelomeric copy-number changes, identification of marker chromosomes, and detection of familial copy-number changes in single genes [68]. The most powerful technique for genome wide screening is array comparative genomic hybridization (aCGH), which has the potential to combine the speed of DNA analysis with a large capacity to scan for subtle genomic abnormalities (approximately additional $10.0 \%$ of karyotying) respective to the resolution of the used arrays [9-11], but is expensive, timeconsuming and requires a high degree of expertise.

Non Invasive Prenatal Diagnosis. The discovery of cell-free fetal DNA (cffDNA) in maternal plasma in 1997 opened up new avenues for prenatal diagnosis $[12,13]$. Fractional concentration of fetal DNA is $\sim 10.0 \%$, coexists with a background of maternal DNA and is present in maternal plasma from approximately the 6th gestational week [14]. Techniques, such as real-time PCR (ReTi-PCR) and digital PCR, provide sufficient sensitivity for reliable non invasive assessment of this cffDNA pool for paternally inherited traits such as sex and RHD status, offering possibilities for non invasive prenatal diagnosis of X-linked disorders (such as Duchenne/Becker muscular dystrophy, Hemophilia A, Hemophilia $\mathrm{B}$, etc.) and $\mathrm{RhD}$ incompatibility, respectively $[15,16]$. By detecting the presence of fetal-specific paternally inherited mutant alleles in maternal plasma, diagnosis of autosomal dominant diseases transmitted by the father could be made non invasively, whereas the absence of such alleles could be used to exclude fetal inheritance of autosomal recessive diseases [14,17-20]. Quantification of cffDNA, specific fetal and maternal DNA and mRNA single nucleotide polymorphism allelic ratios have been used to detect fetal aneuploidies, however, the limitations of these techniques affect the accuracy of the diagnosis [21-23]. Improvements were made after the discovery of the unmethylated SEPINB5 gene that turned out to be the first sex- and polymorphism-independent fetal DNA marker found in maternal plasma [24-27]. The differential methylation of placenta and maternal blood provides a rich source of markers for non invasive prenatal diagnosis, however, further research is needed to render the techniques widely applicable. Implementing the new and robust next generation sequencing techniques in detection of the fetal aneuploidy made the detection for Down's syndrome to have $98.6-100.0 \%$ sensitivity and 96.8$97.9 \%$ specificity $[28,29]$.

Prenatal Diagnosis of Monogenic Diseases. Monogenic diseases are the second most frequent indication for prenatal diagnosis. The incidence of these diseases, depending on the population, is up to $2.0 \%$ newborns. Although there are some biochemical tests and ultrasound findings to screen and identify pregnancies at-risk for specific monogenetic disorders, still the diagnosis is usually established after the fetus is born in couples with no familial history of the disease. In families at-risk for monogenic disease, prenatal diagnosis is used to determine fetal health and to provide adequate management of the pregnancy and prenatal or perinatal treatment. The new developments in prenatal testing using cffDNA and their translation into clinical practice are going to make a difference in selection of pregnancies at-risk for monogenic disorders that need invasive testing.

Prenatal Diagnosis at the Research Centre for Genetic Engineering and Biotechnology (RCGEB)“Georgi D. Efremov," Skopje, Republic of Macedonia. In the last 20 years, the researchers at the RCGEB "Georgi D. Efremov" have performed more than 80 prenatal diagnoses for different monogenic diseases, such as hemoglobinopathies, cystic fibrosis, Duchenne/Becker muscular dystrophy, spinal muscular atrophy, hemophilia A, Lesch Nyhan syndrome, Rett syndrome, phenylketonuria, galactosemia, pseudohypoaldosteronism, etc. [30,31]. The prenatal diagnosis was performed on fetal DNA by using standard molecular genetic techniques for direct diagnosis of the disease or by using informative polymorphic DNA markers for indirect diagnosis.

In 2001, the rapid prenatal detection of the most common chromosomal aneuploidies (chromosomes 13, 18, 21, X and Y) by the multiplex QF-PCR (mQF-PCR) method was introduced at the RCGEB "Georgi D. Efremov" [32,33]. We have developed a one-tube mQF-PCR assay for amplification of 22 highly polymorphic short tandem repeat (STR) markers (at least four by analyzed chromosome) (Table 1). Since then, more than 2200 prenatal diagnoses of common aneuploidies in at-risk preg- 
Table 1. Short tandem repeat markers used in one-tube quantitative fluorescent polymerase chain reaction assay for detection of aneuploidies of chromosomes 13, 18, 21, $\mathrm{X}$ and $\mathrm{Y}$.

\begin{tabular}{|l|c|c|c|c|c|}
\hline & $\begin{array}{c}\text { Chromosome } \\
\mathbf{1 3}\end{array}$ & $\begin{array}{c}\text { Chromosome } \\
\mathbf{1 8}\end{array}$ & $\begin{array}{c}\text { Chromosome } \\
\mathbf{2 1}\end{array}$ & Chromosome X & Chromosome Y \\
\hline STR markers & D13S631 & D18S535 & D21S1414 & AMEL X/Y ${ }^{\mathrm{a}}$ & AMEL X/Y $^{\mathrm{a}}$ \\
\hline & $\mathrm{D} 13 \mathrm{~S} 305$ & $\mathrm{D} 18 \mathrm{~S} 391$ & $\mathrm{D} 21 \mathrm{~S} 1446$ & DXYS218 $^{\mathrm{a}}$ & DXYS218 $^{\mathrm{a}}$ \\
\hline & $\mathrm{D} 13 \mathrm{~S} 258$ & $\mathrm{D} 18 \mathrm{~S} 386$ & $\mathrm{D} 21 \mathrm{~S} 1411$ & TAF9B $^{\mathrm{b}}$ & MYPT2Y $^{\mathrm{c}}$ \\
\hline & $\mathrm{D} 13 \mathrm{~S} 1817$ & $\mathrm{D} 18 \mathrm{~S} 390$ & $\mathrm{D} 21 \mathrm{~S} 1435$ & XHPRT & SRY \\
\hline & & & & DXS6803 & DYS448 \\
\hline
\end{tabular}

${ }^{a}$ Locus on chromosomes $\mathrm{X}$ and $\mathrm{Y}$.

${ }^{\mathrm{b}}$ Locus on chromosomes $\mathrm{X}$ and 3.

${ }^{\mathrm{c}}$ Locus on chromosomes $\mathrm{Y}$ and 2.

nancies have been performed using the mQF-PCR assay as a stand-alone test [34]. It was also used in the prenatal cases of monogenic diseases to control maternal contamination of the fetal material. The prenatal diagnosis was performed on genomic DNA isolated from fetal cells collected by amniocentesis or CVS. Maternal blood samples were analyzed in all blood contaminated amniotic samples and in most chorionic villi samples. No discordant results were obtained when cytogenetic analysis was performed in addition to QF-PCR. Polymorphic duplications involving STR markers D13S631, D21S1441, D18S978 or D18S535 were detected in seven fetuses; in all fetuses the duplications were inherited from one of the parents. Using this method we were also able to determine the parental origin of the aneuploidy [35,36]. In our experience, the QF-PCR method is an efficient, rapid and reliable method for prenatal diagnosis of the most common chromosome aneuploidies. In addition, it can provide information about the origin of the aneuploidy and maternal contamination of the fetal material.

In some "high risk" pregnancies with normal QF-PCR results, we have used MLPA kits to analyze subtelomeric regions and common microdeletion syndromes. In addition to this, aCGH has been employed in prenatal diagnosis of a few fetuses with specific abnormal ultrasound findings.

We have also evaluated the specificity and sensitivity of the real-time quantitative PCR method for non invasive fetal sex determination using cffDNA from maternal plasma. Our initial results showed that this is a promising approach for fetal gender determination in pregnancies at-risk for a fetus with an X-linked disorder [37]. Our recent study of non invasive determination of fetal RHD status, using cffDNA from maternal plasma in $\mathrm{RhD}$ negative pregnant women, showed $100.0 \%$ concordant results with those obtained on fetal DNA from amniocytes or CVS. This is a promising test that can be used in clinical practice for targeted anti-RhD prophylaxis and improvement of management of RHD fetomaternal incompatibility. Using a multi copy marker on Y chromosome (DYS14), we have increased the sensitivity and specificity of the non invasive fetal sex determination using cffDNA. This method will be used in the future for non invasive fetal sex determination in pregnancies at-risk for $\mathrm{X}$-linked disorders. Our further plans include translation of the non invasive tests using cffDNA for diagnosis of monogenic disorders and chromosomal aneuploidies into clinical practice.

\section{ACKNOWLEDGMENTS}

We are grateful to Professor Neil D. Avent for the study including non invasive prenatal determination of fetal sex and RHD status using cffDNA from maternal plasma from pregnant Macedonian women, that was performed during the stay of Dr. Svetlana Madjunkova at the School of Biological and Biomedical Sciences, University of Plymouth, Plymouth, Devon, UK. Dr. Madjunkova's 2-week stay was supported by the FP7 project No. 229458 from the European Commission.

\section{REFERENCES}

1. Kagan KO, Wright D, Spencer K, Molina FS, Nicolaides KH. First-trimester screening for trisomy 21 by free $\beta$-human chorionic gonadotropin and pregnancy-associated plasma protein-A: impact of mater- 
nal and pregnancy characteristics. Ultrasound Obstet Gynecol. 2008; 31(5): 493-502.

2. Mujezinovic F, Alfirevic Z. Procedure-related complications of amniocentesis and chorionic villus sampling: a systematic review. Obstet Gynecol. 2007; 110(3): 687-694.

3. Driscoll DA, Gross S. Clinical practice. Prenatal screening for aneuploidy. N Engl J Med. 2009; 360(24): 2556-2562.

4. Cirigliano V, Ejarque M, Canadas MP, et al. Clinical application of multiplex quantitative fluorescent polymerase chain reaction (QF-PCR) for the rapid prenatal detection of common chromosome aneuploidies. Mol Hum Reprod. 2001; 7(10): 1001-1006.

5. Faas BH, Cirigliano V, Bui TH. Rapid methods for targeted prenatal diagnosis of common chromosome aneuploidies. Semin Fetal Neonatal Med. 2011; 16(2): 81-87.

6. Willis AS, van den Veyver I, Eng CM. Multiplex ligation-dependent probe amplification (MLPA) and prenatal diagnosis. Prenat Diagn. 2012; 32(4): $315-$ 320.

7. Bocian E, Kasprzycka J, Jakubow-Durska K, Luszczek A, Bernaciak J. [Usefulness of MLPA technique for rapid prenatal detection of aneuploidy. Results of 409 diagnostic studies]. Ginekol Pol. 2011; 82(9): 680-684.

8. Konialis C, Hagnefelt B, Sevastidou S, et al. Uncovering recurrent microdeletion syndromes and subtelomeric deletions/duplications through nonselective application of a MLPA-based extended prenatal panel in routine prenatal diagnosis. Prenat Diagn. 2011; 31(6): 571-577.

9. Rickman L, Fiegler H, Shaw-Smith C, et al. Prenatal detection of unbalanced chromosomal rearrangements by array CGH. J Med Genet. 2006; 43(4): 353-361.

10. Brady PD, Devriendt K, Deprest J, Vermeesch JR. Array-based approaches in prenatal diagnosis. Methods Mol Biol. 2012; 838: 151-171.

11. Fiorentino F, Caiazzo F, Napolitano S, et al. Introducing array comparative genomic hybridization into routine prenatal diagnosis practice: a prospective study on over 1000 consecutive clinical cases. Prenat Diagn. 2011; 31(13): 1270-1282.

12. Dennis Lo YM, Chiu RW. Prenatal diagnosis: progress through plasma nucleic acids. Nat Rev Genet. 2007; 8(1): 71-77.

13. Lo YM, Corbetta N, Chamberlain PF, et al. Presence of fetal DNA in maternal plasma and serum. Lancet. 1997; 350(9076): 485-487.

14. Lun FM, Tsui NB, Chan KC, et al. Noninvasive prenatal diagnosis of monogenic diseases by digital size selection and relative mutation dosage on DNA in maternal plasma. Proc Natl Acad Sci USA. 2008; 105(50): 19920-19925.

15. Hromadnikova I, Vechetova L, Vesela K, Benesova B, Doucha J, Vlk R. Non-invasive fetal RHD and RHCE genotyping using real-time PCR testing of maternal plasma in $\mathrm{RhD}$-negative pregnancies. J Histochem Cytochem. 2005; 53(3): 301-305.

16. Tsui NB, Kadir RA, Chan KC, et al. Noninvasive prenatal diagnosis of hemophilia by microfluidics digital PCR analysis of maternal plasma DNA. Blood. 2011; 117(13): 3684-3691.

17. Saito H, Sekizawa A, Morimoto T, Suzuki M, Yanaihara T. Prenatal DNA diagnosis of a singlegene disorder from maternal plasma. Lancet. 2000; 356(9236): 1170.

18. Chiu RW, Lau TK, Leung TN, Chow KC, Chui DH, Lo YM. Prenatal exclusion of $\beta$ thalassaemia major by examination of maternal plasma. Lancet. 2002; 360(9338): 998-1000.

19. Li Y, Di Naro E, Vitucci A, Zimmermann B, Holzgreve W, Hahn S. Detection of paternally inherited fetal point mutations for $\beta$-thalassemia using size-fractionated cell-free DNA in maternal plasma. JAMA. 2005; 293(7): 843-849.

20. Legler TJ, Muller SP, Haverkamp A, Grill S, Hahn S. Prenatal RhD testing: a review of studies published from 2006 to 2008. Transfus Med Hemother. 2009; 36(3): 189-198.

21. Zhong XY, Burk MR, Troeger C, Kang A, Holzgreve W, Hahn S. Fluctuation of maternal and fetal free extracellular circulatory DNA in maternal plasma. Obstet Gynecol. 2000; 96(6): 991-996.

22. Chiu RW, Chan KC, Gao Y, et al. Noninvasive prenatal diagnosis of fetal chromosomal aneuploidy by massively parallel genomic sequencing of DNA in maternal plasma. Proc Natl Acad Sci USA. 2008; 105(51): 20458-20463.

23. Tsui NB, Akolekar R, Chiu RW, et al. Synergy of total PLAC4 RNA concentration and measurement of the RNA single-nucleotide polymorphism allelic ratio for the noninvasive prenatal detection of trisomy 21. Clin Chem. 2010; 56(1): 73-81.

24. Tong YK, Chiu RW, Akolekar R, et al. Epigeneticgenetic chromosome dosage approach for fetal trisomy 21 detection using an autosomal genetic reference marker. PLoS One. 2010; 5(12): e15244.

25. Chiu RW, Chim SS, Wong IH, et al. Hypermethylation of RASSF1A in human and rhesus placentas. Am J Pathol. 2007; 170(3): 941-950.

26. Chim SS, Jin S, Lee TY, et al. Systematic search for placental DNA-methylation markers on chromosome 21: toward a maternal plasma-based epigenetic test for fetal trisomy 21. Clin Chem. 2008; 54(3): 500-511. 
27. Brown L, Brown G, Vacek P, Brown S. Aneuploidy detection in mixed DNA samples by methylationsensitive amplification and microarray analysis. Clin Chem. 2010; 56(5): 805-813.

28. Palomaki GE, Kloza EM, Lambert-Messerlian GM, et al. DNA sequencing of maternal plasma to detect Down syndrome: an international clinical validation study. Genet Med. 2011; 13(11): 913-920.

29. Chiu RW, Akolekar R, Zheng YW, et al. Noninvasive prenatal assessment of trisomy 21 by multiplexed maternal plasma DNA sequencing: large scale validity study. BMJ. 2011; 342:c7401.

30. Kocheva S, Trivodalieva S, Plaseska-Karanfilska D, Vlaski-Jekic S, Kuturec M, Efremov GD. Prenatal diagnosis in Macedonian Duchenne muscular distrophy families. Balkan J Med Genet. 2008; 11(2): 59-63.

31. Kocheva SA, Plaseska-Karanfilska D, Trivodalieva S, Kuturec M, Vlaski-Jekic S, Efremov GD. Prenatal diagnosis of spinal muscular atrophy in Macedonian families. Genet Test. 2008; 12(3): 391-393.

32. Arsovska S, Dimcev P, Kaeva M, Efremov GD, PlaseskaKaranfilska D. Rapid prenatal diagnosis of common aneuploidies by quantitative fluorescent polymerase chain reaction. Proceedings of the 5th Balkan Meeting on Human Genetics, Sofia, Bulgaria, August 28-September 1,$2002 ; 145$.

33. Plaseska-Karanfilska D, Talaganova S, Trivodalieva $\mathrm{S}$, Efremov GD. Prenatal diagnosis of aneuploi- dies of chromosomes 13, 18, 21, X and Y by QFPCR in the Republic of Macedonia. Proceedings of the European Human Genetics Conference, Nice, France, June 16-19, 2007. Eur J Hum Genet. 2007; 140.

34. Plaseska-Karanfilska D, Madjunkova S, Maleva I, Kiprijanovska S. Rapid prenatal diagnosis of common chromosome aneuploidies using quantitative fluorescent (QF)-PCR: 10 years experience in a center from the Republic of Macedonia. Proceedings of the 12th International Congress of Human Genetics, Montreal, Canada, October 11-15, 2011; 1369W.

35. Talaganova S, Trivodalieva S, Arsovska S, Kaeva M, Efremov GD, Plaseska-Karanfilska D. The parental and meiotic origin of extra chromosome 21 in Down syndrome patients. Proceedings of the 7th Balkan Meeting on Human Genetics, Skopje, Macedonia, August 31-September 2, 2006. Balkan J Med Genet. $2006 ; 118$.

36. Kiprijanovska S, Trivodalieva S, Gefremov GD, Plaseska-Karanfilska D. The parental origin of chromosome aneuploidies. Proceedings of the 8th Balkan Meeting of Human Genetics, Cavtat, Croatia, May 14-17, 2009; 23.

37. Davalieva K, Dimcev P, Efremov GD, PlaseskaKaranfilska D. Non-invasive fetal sex determination using real-time PCR. J Matern Fetal Neonatal Med. 2006; 19(6): 337-342. 